\title{
Voluntary self-poisoning as a cause of admission to a tertiary hospital internal medicine clinic in Piraeus, Greece within a year Charalambos Tountas ${ }^{1}$, Alexios Sotiropoulos ${ }^{* 2}$, Stathis A Skliros3, Vasiliki Kotsini ${ }^{2}$, Theodoros A Peppas ${ }^{2}$, Elias Tamvakos ${ }^{2}$ and Stavros Pappas ${ }^{2}$
}

Address: ${ }^{1}$ Academic Dpt of Medicine, Hippokration General Hospital, Athens, Greece, ${ }^{2} 3$ rd Dpt. Of Internal Medicine, Nikea General Hospital, Piraeus, Greece and 3Clinic of Family and Social Medicine, University of Crete, Iraklion, Greece

E-mail: Charalambos Tountas - stipapas@hellasnet.gr; Alexios Sotiropoulos* - stipapas@ hellasnet.gr;

Stathis A Skliros - ESKLIROS@OTENET.GR; Vasiliki Kotsini - ESKLIROS@OTENET.GR; Theodoros A Peppas - stipapas@hellasnet.gr;

Elias Tamvakos - kyn@nethouse.gr; Stavros Pappas - stipapas@hellasnet.gr

${ }^{*}$ Corresponding author

Published: 2 October 2001

Received: 3 July 2001

BMC Psychiatry 200I, I:4

Accepted: 2 October 200

This article is available from: http://www.biomedcentral.com//47/-244X/I/4

(C) 200 I Tountas et al; licensee BioMed Central Ltd. Verbatim copying and redistribution of this article are permitted in any medium for any non-commercial purpose, provided this notice is preserved along with the article's original URL. For commercial use, contact info@biomedcentral.com

\begin{abstract}
Background: Out of 1705 patients hospitalised for various reasons in the $3^{\text {rd }}$ Internal Medicine Department of the Regional General Hospital of Nikaea, in Piraeus, 146(8,5\%) persons were admitted for drug intoxication between November 1999 and November 2000.
\end{abstract}

Methods: On average, these persons [male 50(34,2\%) - female 96(65,8\%)] were admitted to the hospital within 3.7 hours after taking the drug.

Results: The drugs that were more frequently taken, alone or in combination with other drugs, were sedatives (67.1\%), aspirins and analgesics (mainly paracetamol) (43.5\%). $38.3 \%$ of patients had a mental illness history, $31.5 \%$ were in need of psychiatric help and $45.2 \%$ had made a previous suicide attempt. No death occurred during the above period and the outcome of the patients' health was normal. After mental state examination, the mental illnesses diagnosed were depression (20.96\%), psychosis (15.32\%), dysthymic disorder (16,2\%), anxiety disorder (22.58\%) and personality disorder (8.87\%).

Conclusions: Self-poisoning remains a crucial problem. The use of paracetamol and sedatives are particularly important in the population studied. Interpersonal psychiatric therapy may be a valuable treatment after people tried to poison themselves.

\section{Background}

Voluntary drug intoxication is a major medical and social problem in developed countries today and the most common way of attempting suicide. In the course of time the rate of incidence has increased. Considering the social aspect of the problem, we can see that the causes of this phenomenon are various.

The primary objective of the present paper is recording all cases of drug intoxication (defined as voluntary drug overdosing or taking of toxical substances voluntarily) 
hospitalized in an internal medicine department within a year. Moreover, we have studied the incidence rate and the distribution in terms of sex, age, marital status, employment, the kind of toxical substance taken, the outcome and the causes. The secondary, equally important objective of the paper is estimating the psychiatric morbidity rate in patients with drug intoxication and examining the significance of psychiatric help for these patients. The highest rates for drug overdoses were found for female attempters. At this conclusion arrived other studies too. There is a need, especially for areas with high frequencies for certain methods, to understand the factors involved, to develop new and specific prevention projects and to monitor their effects [1].

\section{Patients and methods}

This study includes all cases of drug intoxication hospitalized in the $3^{\text {rd }}$ internal medicine department of the Regional General Hospital of Nikea between November 1999 and November 2000.

On a total of 1705 patients admitted to the hospital, 146 $(8,5 \%)$ were admitted for drug intoxication. In all cases the diagnosis of drug intoxication was based on information provided by the patient himself or by his/her closest relatives. Patients taking any toxical or pharmaceutical substance by accident or through ignorance were excluded, whereas those taking toxical substances were included. Most patients (85\%) were subject to a mental state examination conducted by a specialized psychiatrist (there was no use of an adjusted mental health assessment scale).

The usual laboratory tests included blood test, sugar, urea, creatinine and electrolytes measurements, a thoracic radiography and an electrocardiogram. In some patients blood gases and bicarbonates were tested.

The hepatic function was examined on a daily basis in patients who had taken paracetamol. Acetylcysteine was administered as an antidote, if the dose taken was very high $(>100 \mathrm{mg} / \mathrm{kg})$. In case the patient had taken a toxical dose of benzodiazepines or opiates, in case disorders occurred in the level of conscience (confusion, lethargy, coma) or in the respiratory function due to suppression, flumazenil or hydrochloride naloxone were administered, respectively, until recovery.

Treatment included hydration, supporting the cardiac, respiratory and renal function, administration of the suitable antidote after consulting the National Poison Control Center, elective administration of carbon. Patients admitted to the hospital within a few hours after taking the drug ( $<6$ hours) were subject to gastric lavage.
Results were compared with data from similar studies conducted both in Greece and abroad and specific comparisons were made by the use of the chi-square test.

\section{Results}

1705 patients in total were hospitalized in the clinic within a year (01.11.99 - 01.11.00). 146 of them were admitted to the hospital for drug intoxication (8.5\%).

96 of these patients were women (65.8\%) 15 to 65 years of age and 50 were men (34.2\%) 16 to 74 years of age. The ratio of men to women was $1 / 1.92$. The average age of women hospitalized for drug intoxication was $29.82 \pm$ 11.72 , whereas the average age of men was $33.09 \pm 12.01$. Considering the distribution of patients by age group and by sex, it is obvious that most cases of drug intoxication were persons aged less than 49 years old, whereas the incidence rate in women is superior to that in men, especially as regards to younger women. On the contrary after the age of 50 the incidence rate decreases considerably (5.46\%) [Table 1].

Table I: Patient distribution by age group

\begin{tabular}{lrrrrrr}
\hline Age Groups & Men & \multicolumn{3}{l}{ Women } & \multicolumn{3}{l}{ Total } \\
& & & & & & \\
& N & $\%$ & N & $\%$ & N & $\%$ \\
& & & & & & \\
\hline & & & & & & \\
$20-19$ & 6 & $(12 \%)$ & 25 & $(26,05 \%)$ & 31 & $(21,23 \%)$ \\
$30-39$ & 15 & $(30 \%)$ & 30 & $(31,25 \%)$ & 45 & $(30,82 \%)$ \\
$40-49$ & 14 & $(28 \%)$ & 18 & $(18,75 \%)$ & 32 & $(21,94 \%)$ \\
$50-59$ & 13 & $(26 \%)$ & 17 & $(17,70 \%)$ & 30 & $(20,55 \%)$ \\
$60-69$ & - & - & 5 & $(5,20 \%)$ & 5 & $(3,42 \%)$ \\
$70-79$ & 1 & $(2 \%)$ & 1 & $(1,05 \%)$ & 2 & $(1,36 \%)$ \\
TOTAL & 1 & $(2 \%)$ & - & - & 1 & $(0,68 \%)$ \\
& 50 & $100 \%$ & 96 & $100 \%$ & 14 & $100 \%$ \\
& & & & & 6 & \\
\hline
\end{tabular}

Regarding the marital status of these women 46(48\%) were single, 41 (42.7\%) were married and $9(9.3 \%)$ were divorced, whereas $44(88 \%)$ men were single, $3(6 \%)$ were married and $3(6 \%)$ were divorced. Married women were considerably more compared to married men ( $\mathrm{p}$ o.oo1).

Regarding education, it seems that women and men who had received secondary education attempted drug intoxication more often compared to those of higher education (women: $69.9 \%$ versus $16.4 \%$ ) - men: $75.9 \%$ versus $6.9 \%)$. However, this difference was not statistically significant. 
Regarding employment, 39 women (40.6\%) were housewives, $15(15.6 \%)$ were employed in the private sector and $14(14.6 \%)$ were students. 19 men (38\%) were unemployed, $11(22 \%)$ were students or pupils and $10(20 \%)$ were employed in the private sector.

$72.4 \%$ of patients were admitted to the hospital within 3 hours after attempted suicide, whereas after 4 hours the rate of patients admitted to the hospital amounted to $82.9 \%$.

Out of 146 patients, 71 (48.6\%) took one pharmaceutical substance, 40 patients (27.4\%) took two substances, 31 patients $(21.2 \%)$ took three substances and 42 patients (2.8\%) took four or more substances.

The drugs taken more frequently, alone or in combination with other drugs, were sedatives (67.1\% [98/146]), especially the subgroup of benzodiazepines (69.4\% [68/ $98]$ ), as well as aspirin and analgesics (mainly paracetamol) (43.5\% [63/146). Ethanol alone or in combination with other drugs was used only by $6.15 \%(9 / 146)$ of patients. $13.7 \%$ of patients $(20 / 146)$ were drug users who took mostly heroine (Table 2 ).

Table 2: Drugs taken

\begin{tabular}{lll}
\hline $\begin{array}{l}\text { Drugs (taken alone or in combination } \\
\text { with other drugs) }\end{array}$ & Number & $\%$ \\
\hline & & \\
\hline I. Sedatives & $98 / 146$ & $(67,1 \%)$ \\
-Benzodiazepines & $68 / 98$ & \\
-Antidepressants & $20 / 98$ & \\
-Antipsychotic drugs & $10 / 98$ & \\
2. Analgesics & $63 / 146$ & $(43,5 \%)$ \\
-NSAIDs & $37 / 63$ & \\
-Paracetamol & $26 / 63$ & \\
3. Heroine and hallucinogens & $20 / 146$ & $(13,7 \%)$ \\
4. Alcohol & $9 / 146$ & $(6,15 \%)$ \\
5. Other & $52 / 146$ & $(35,6 \%)$ \\
\end{tabular}

$38.3 \%$ of patients had a history of mental illness, $45.2 \%$ had attempted drug intoxication before and $31.5 \%$ of patients had needed psychiatric help. Patients who had attempted drug intoxication repeatedly had a history of mental illness at a significantly greater rate compared to the total number of patients (38.3\%) (p 0.001). Upon admission to the clinic mild to major toxicity was found in $56 \%$ of patients (complications in various systems). More precisely, disorders in the level of conscience appeared in 57 patients (39.1\%). Out of 57 patients 17 (30\%) were admitted to hospital in a coma (Glasgow scale) (Table 3).
Table 3: Clinical state of patients by admissi on to hospital

\begin{tabular}{lll}
\hline Clinical State & Number & $\%$ \\
\hline & & \\
I. Without symptoms & $64 / 146$ & $(44 \%)$ \\
2. Disorders in level of conscience & $57 / 146$ & $(39,1 \%)$ \\
-Coma & $17 / 57$ & \\
3. Disorders by other systems & $25 / 146$ & $(16,9 \%)$ \\
& & \\
\hline
\end{tabular}

The outcome was favourable for all patients with no death occurring. A small percentage of the patients [2.1\%] needed to be transferred to the Intensive Care Unit and $11 \%$ of the patients were transferred to the psychiatric department for further assessment and treatment due to the severity of their psychiatric problems. More than half [51.4\%] of the patients were discharged normally, 30.1\% of patients left the hospital at their own will and $5.5 \%$ of patients fled without notifying the hospital. The average length of hospital stay for $90 \%$ of patients was 2.4 days.

The main mental illnesses diagnosed after the mental state examination (according to the international classification criteria DSM-IV - R) were depression (20.96\%), psychosis (15.32\%), personality disorder (8.87\%), dysthymic disorder (16.2\%) and anxiety disorder (22.58\%) [Table 4].

Table 4: Psychiatric diagnosis [( $124 / 146) 85 \%$ of patients]

\begin{tabular}{lll}
\hline Diagnosis & Number & $\%$ \\
& & \\
\hline & & \\
I/. Emotional Disorders & & \\
I. Severe and atypical depressions & $26 / 124$ & $(20,96 \%)$ \\
2. Bipolar disorder & $2 / 124$ & $(1,61 \%)$ \\
3. Dysthymic disorder & $20 / 124$ & $(16,2 \%)$ \\
II /. Psychotic disorder & $19 / 124$ & $(15,32 \%)$ \\
III/. Anxiety disorder & $28 / 124$ & $(22,58 \%)$ \\
IV/. Personality disorder & $1 / / 124$ & $(8,87 \%)$ \\
VI. Withdrawal syndrome & $2 / 124$ & $(1,61 \%)$ \\
VII. Toxicomania & $15 / 124$ & $(12,09 \%)$ \\
VIII. Organic psychotic syndrome & $1 / 124$ & $(0,8 \%)$ \\
\end{tabular}

\section{Discussion}

One of the most frequent causes for admission to a tertiary hospital is drug intoxication, since $8.5 \%$ of total admissions are due to drug intoxication. This rate is higher compared to that found in other studies conducted in Greece, but it is significantly lower compared to the cor- 
responding rate in the European Union and American countries [2,3]. In regards to admission in a hospital due to drug intoxication, there was a statistically significant increase (123/5.534 vs 146/1705 p 0.001) noted in suchlike Medical admissions in comparison with the results of a previous study conducted in the same hospital from August 1986 to August 1987 [4].

According to comparative studies conducted in USA and other European countries there has been a statistically significant increase in the number of drug intoxication cases during the eighties [5] According to data from the Poison Control Center drug intoxication cases have increased by $37.3 \%$ from 1980 to 1994 . However, these data are based mainly on the number of telephone calls the Poison Control Center has received, including to some extent on accidental cases of poisoning and are not based on the number of patients admitted to hospital [6].

In the present study the ratio of men to women was 1/ 1.92. In similar studies conducted in the same hospital in 1977 and in 1987 but related with attempted suicides (94\% drug intoxication) the ratio of men to women was $1 / 3.88$ and $1 / 7.7$, respectively $[7,8]$. It is likely that this development is due to the emancipation of women, due to the fact that women entered labour market tackling successfully their daily problems and due to the continuous increase in the unemployment rate. Due to social beliefs, unemployment is still an important factor of emotional stress, especially for men. However, a few data were found in Greek and international literature for documenting this assumption [5,9,10].

Most cases of drug intoxication (approximately 2/3) are mostly single women and married women who have received a secondary education. The causes are mainly conflicts with other family members or problems with their husbands. The average age is lower than that of men. The fact that the females prevail is related to the personality, the emotional features and the idiosyncrasy of women [11]. On the contrary regarding males, due to the high unemployment rate the indication is that employment plays an important role in ensuring a normal mental state. Pupils and students, both boys and girls, make attempts quite often. In these cases the causes are associated with emotional changes and problems they face in school, especially during examinations [12]. We can come to this conclusion, if we consider the distribution of drug intoxications during the whole year. There is a considerable increase in drug intoxication cases during summer [13].

In comparison with other European countries the drugs taken are quite_similar, but in general there are differences in the drugs preferred by persons admitted for drug intoxication [1]. In Greece benzodiazepines, aspirin and paracetamol are the drugs most frequently chosen, as were antidepressants ( $\sim 10 \%$ of all drugs) in a previous similar study [4]. Persons likely to attempt suicide show preference to these drugs probably because they are not difficult to obtain and may even have been prescribed to them by a phycisian. On the contrary in the United Kingdom paracetamol alone or in combination with other drugs is the drug used mostly in attempted suicide [14]. Persons attempting suicide in Greece may also use alcohol but to a lesser degree compared to other European countries. According to some studies conducted in other European countries the drug preferred mostly by persons attempting suicide is ethanol [15]. $45 \%$ of patients had attempted drug intoxication repeatedly in the past and $38 \%$ of patients had a mental illness history. It is obvious that these persons need psychiatric help, so that they do not make another attempt. According to studies psychiatric help has a positive impact, as far as the survival of these persons is concerned $[9,16]$. Due to the great possibility of a relapse psychiatric help is extremely necessary.

The fact that the clinical state of most persons attempting suicide is good when admitted to the hospital and the fact that most of them recover without any problems indicate that most of them do not wish to die [17]. No death has been registered, since severe cases are transferred directly to Intensive Care Units and modem treatment methods are applied [18]. In Greece the mortality rate due to suicide is lower compared to other countries [19]. The high rate of repeated drug intoxication events (45\%) is considered to be an independent high risk factor, which increases mortality rate [20].

We may conclude that drug intoxication is a problem that occurs frequently with a medical as well as social aspect. The increased use of antidepressants in self-poisoning is an alarming signal and caution in their prescription seems to be indicated [9]. Causes are associated with both individual and socioeconomic parameters, such as relationships among family members, unemployment, insufficient education, alcohol and drug misuse. Since most cases have a history of mental illness mostly depression [21], and due to the repeated drug intoxication events, it is obvious that these persons definitely need psychiatric help and support.

\section{Competing interests}

None declared

\section{References}

I. Michel K, Ballinari P, Bille-Brade U, et al: Methods used for parasuicide: results of the WHO/EURO multicentre study on parasuicide. Soc Phychiatry Phychiatr Epidemiol 2000, 35(4): I 56-I 63

2. Voyiaki S, Efstratopoulos A: Drug intoxication aiming at suicide. Recent experience from an internal medicine clinic of a gen- 
eral hospital in Athens. Archives of the Hellenic Medical Society 1996, I3(2): $|36-| 4 \mid$

3. Kessel N: Self-poisoning. Part I. Br Med J 1965, 2: I 265-I270

4. Dimakopoulou A, Rontos I, Spyropoulos I, Papamichael E: Preliminary observations during the first year of running of Psychiatric Consultation Services in the Regional General Hospital of Nikea "Damon Vasiliou". ENCEPHALOS 1989, 26:168-172

5. Rygnestad T, Hauge L: Epidemiological, social and psychiatric aspects in self-poisoned patients. A prospective, comparative study from Trondheim, Norway (1978-1987. Soc Psychiatry Epidemiol 1991, 26(2):53-62

6. Poison Control Centre, Children's Hospital "Aglaia Kyriakou". Twenty years of experience and contribution (19751995). Athens 1995

7. Rontos I, Dimakopoulou A, Psilolignos P, Christodoulou CH, Rontos $\mathrm{K}$ : Attempted suicides in the area of the Regional General Hospital of Nikea "Damon Vasiliou". Investigating demographic, social and psychiatric characteristics. ENCEPHALOS 1989, 26:150-155

8. Terentios E, Komaitis G, Kranidiotis P: Psychiatric and social observations on attempted suicides in the area of the Regional General Hospital of Nikea in Piraeus: ENCEPHALOS I, 328 (Proceedings of the 7th Panhellenic Congress of Neurology and Psychiatry) 1977

9. Milicevic G, Pric H: Self-poisonings with psychopharmacological agents in Zagreb. Hum Exp Toxicol 1991, 10(5):305-309

10. Welcher B, Rubin P, Nordentoft M: Admission of self-poisoned patients during one year at the Poisoning Treatment Center, Copenhagen, Denmark. Acta Psychiatr Scand Suppl 1993, 371:38-44

II. Eawton O, Gray J, Osborn M, Cole D: Adolescents who take overdoses: Their characteristic problems and contacts with Helping Agencies. Brit J Psychiat 1982, 140:1 I8-123

12. Bazas TH, Gemos G, Stefanis K, Trichopoulos D: Incidence of seasonal distribution and demographic characteristics of suicides in Greece. Materia Medica Greca 1978, 6:38-46

13. Billis A, Tsirogiannis D, Vosnidis G, Manos I, Pitsavos CH: Voluntary drug intoxications (Observations on 734 cases) Material Medical Greca | $9786 \mid-65$

14. Keil M, Schafer V, Lorcher U, Schneidor M, Leitz FU, Reuhl J: Preliminary results of an interdisciplinary survey of drug victims. Forensic Sci Int 1993, 62:147-149

15. Jacobsen D, Frederischen PS, Knutsen KM, Sorum Y, Talseth T, Odengaard OR: A prospective study of 1212 cases of acute poisoning: general epidemiology. Hum Toxicol 1984, 3(2):93-106

16. Suokas J, Lonnqvist J: Outcome of attempted suicide and psychiatric consultation: risk factors and suicide mortality during a five-year follow-up. Acta Psychiatr Scand I991, 84(6):545-549

17. Caravati E, McElwee NE: Use of clinical toxicology resources by Emergency Physicians and its impact on poison control centers. Ann. Emerg. Med. 1991, 20:147-150

18. Grett AS: Implications of discordance between clinical impression and toxicology analysis in drug overdose. Arch Intern Med 1988, | 48:437-44|

19. WHO: World Health Statistics Report, WHO, Geneva 1976, 29:396

20. Nielsen B, Petersen P, Rask PH, Krarur G: Suicide and other causes of death in patients admitted for attempted suicide. ( 10 Year follow-up). Ugeskr Laeger 1995, I 57(15):2 I 49-2I53

2I. Papamichael E, Pertesi E, Spiropoulos J, et al: First years of experience in consultation-liaison Psychiatry in Greece: Proc. of the 8th World Congress of Psychiatry, 262
Publish with BioMed Central and every scientist can read your work free of charge

"BioMedcentral will be the most significant development for disseminating the results of biomedical research in our lifetime."

Paul Nurse, Director-General, Imperial Cancer Research Fund

Publish with BMC and your research papers will be:

- available free of charge to the entire biomedical community

- peer reviewed and published immediately upon acceptance

- cited in PubMed and archived on PubMed Central

- yours - you keep the copyright

Submit your manuscript here:

http://www.biomedcentral.com/manuscript/ 